\title{
Mass concentrations of black carbon measured by four instruments in the middle of Central East China in June 2006
}

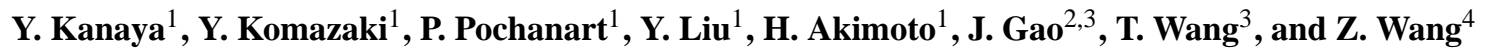 \\ ${ }^{1}$ Frontier Research Center for Global Change, Japan Agency for Marine-Earth Science and Technology, Yokohama, Japan \\ ${ }^{2}$ Environment Research Institute, Shandong University, Jinan, China \\ ${ }^{3}$ Department of Civil and Structural Engineering, The Hong Kong Polytechnic University, Hong Kong, China \\ ${ }^{4}$ LAPC/NZC, Institute of Atmospheric Physics, Chinese Academy of Sciences, Beijing, China
}

Received: 20 June 2008 - Published in Atmos. Chem. Phys. Discuss.: 5 August 2007

Revised: 25 November 2008 - Accepted: 25 November 2008 - Published: 18 December 2008

\begin{abstract}
Mass concentrations of black carbon (BC) were determined in June 2006 at the top of Mount Tai $\left(36.26^{\circ} \mathrm{N}\right.$, $117.11^{\circ} \mathrm{E}, 1534 \mathrm{~m}$ a.s.l.), located in the middle of Central East China, using four different instruments: a multi-angle absorption photometer (5012 MAAP, Thermo), a particle soot absorption photometer (PSAP, Radiance Research), an ECOC semi-continuous analyzer (Sunset Laboratory) and an Aethalometer (AE-21, Magee Scientific). High correlation coefficients $\left(R^{2}>0.88\right)$ were obtained between the measurements of the $\mathrm{BC}$ mass concentrations made using the different instruments. From the range of the slopes of the linear least-square fittings, we concluded that BC concentrations regionally-representative of the area were measured in a range with a maximum-to-minimum ratio of 1.5 (an exception was that the $\mathrm{BC}\left(\mathrm{PM}_{2.5}\right)$ concentrations derived from MAAP were $\sim 2$ times higher than the optical measurements $\left(\mathrm{PM}_{2.5}\right)$ derived from the ECOC analyzer). While this range is significant, it is still sufficiently narrow to better constrain the large and highly uncertain emission rate of $\mathrm{BC}$ from Central East China. In detail, two optical instruments (the MAAP and the PSAP equipped with a heated inlet $400^{\circ} \mathrm{C}$ ) tended to give higher concentrations than the thermal EC concentrations observed by the ECOC analyzer. The ratios of optical $\mathrm{BC}$ to thermal EC showed a positive correlation with the OC/EC ratio reported by the ECOC analyzer, suggesting two explanations. One is that the optical instruments overestimated BC concentrations in spite of careful cancellation of the scattering effect in the MAAP instrument and the
\end{abstract}

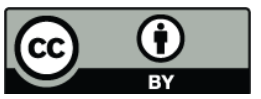

Correspondence to: Y. Kanaya (yugo@jamstec.go.jp ) expected evaporation of volatile species by heating the inlet of the PSAP instrument. The other is that the determined split points between OC and EC were too late when a large amount of OC underwent charring during the analysis, resulting in an underestimation of EC by the ECOC analyzer. High ratios of optical $\mathrm{BC}$ to thermal $\mathrm{EC}$ were recorded when the $\mathrm{NO}_{\mathrm{x}} / \mathrm{NO}_{\mathrm{y}}$ ratio was low, implying the coating of the particles became thicker in an aged air mass and thus resulted in the optical instruments overestimating $\mathrm{BC}$ concentrations because of the lensing effect.

\section{Introduction}

Black carbon (BC) aerosol particles are an important component of the atmosphere contributing to global warming. A global average of the direct radiative forcing at the top of the atmosphere due to the present day increased atmospheric loading of $\mathrm{BC}$ has been estimated to be in the range of +0.2 $0.6 \mathrm{~W} \mathrm{~m}^{-2}$ (IPCC, 2007). The large uncertainty range partially stems from the uncertainties in the estimated BC emission rate and the absolute concentration in the atmosphere. In particular, the emission rate of $\mathrm{BC}$ from China is estimated to be large and having large uncertainty. Bond et al. (2004) gave a central value of the emission rate of $\mathrm{BC}$ from contained combustion (fossil and biofuel combustion excluding open burning) in China as $1365 \mathrm{Gg} \mathrm{yr}^{-1}$ for 1996 , nearly $30 \%$ of the global emission rate $\left(4626 \mathrm{Gg} \mathrm{yr}^{-1}\right)$. Even when the contribution from open burning $\left(124 \mathrm{Gg} \mathrm{yr}^{-1}\right)$ is added, the fraction of the emission rate from China $\left(1489 \mathrm{Gg} \mathrm{yr}^{-1}\right)$ is still large $\left(\sim 19 \%\right.$ of the global value, $\left.7951 \mathrm{Gg} \mathrm{yr}^{-1}\right)$. The ratios of their highest estimation to their lowest estimation

Published by Copernicus Publications on behalf of the European Geosciences Union. 
of the emission rates are 3.9 for both contained combustion and open burning in China. Streets et al. (2003) estimated the total emission rate from China to be $1049 \mathrm{Gg} \mathrm{yr}^{-1}$ in 2000 with an uncertainty of a factor of 5.8 (as the $95 \%$ confidence interval). The ratio between their highest and lowest estimates is as high as a factor of 34 . In the vast geographical area that makes up China, Central East China (CEC) is a region with outstandingly high emission rates of atmospheric pollutants. Although measurements of $\mathrm{BC}$ have been undertaken at several urban sites in the region (Bergin et al., 2001; He et al., 2001; Dan et al., 2004; Yang, F. et al., 2005; Ye et al., 2003; Cao et al., 2007; Yang, H. et al., 2005), measurements at rural/remote locations with regional representativeness have only been made at Lin'an (Zhejiang Province, $53 \mathrm{~km}$ west of Hangzhou) in November 1999 and in February-April 2001 (Xu et al., 2002; Wang et al., 2004), at Xianghe (70 km southeast of Beijing) in March 2005 (Li et al., 2007), and at Shangdienzi (about $150 \mathrm{~km}$ northeast of Beijing) from 2003 to 2005 (Yan et al., 2008). In these studies, the observed $\mathrm{BC}$ concentrations have not been compared with model predictions. During the ACE-Asia and TRACE$P$ field campaigns performed in the downwind area of China in February-April 2001, modeled BC concentrations were compared to observed values, testing the emission rate of BC from China (e.g., Woo et al., 2003; Carmichael et al., 2003a, b; Uno et al., 2003). However, no solid conclusion was reached particularly for the validity of the Chinese emission rate. Therefore no stringent studies have been performed testing the validity of the emission rate through a comparison of the observed and modeled mass concentrations of $\mathrm{BC}$ in China.

Generally, two approaches are employed for measurements of BC concentrations. One is the optical method, in which measurements of optical transmittance, reflectance, or their combination are undertaken with respect to a filter on which the aerosol particles are deposited. The measured absorbance or the attenuation of light through the filter is related to the mass of $\mathrm{BC}$. The other type is the thermal method, in which organic carbon (OC) and elemental carbon (EC) collected on a filter are successively evaporated under $\mathrm{He}$ and $\mathrm{O}_{2} / \mathrm{He}$ atmospheres with thermal evolution and then the evolved carbon is quantified as $\mathrm{CO}_{2}$ or $\mathrm{CH}_{4}$. During the evaporation, the optical transmittance (or reflectance) of the filter is monitored, which typically decreases first and then increases, due to the charring of OC during the analysis. The OC and EC are separated by defining a split point where the original optical transmittance (or reflectance) is recovered during the temperature-rising program, to correct for the charring. Two thermal protocols are often used; those of the Interagency Monitoring of Protected Visual Environments (IMPROVE) of the Desert Research Institute (Chow et al., 2001) and the National Institute for Occupational Safety and Health (NIOSH) (Birch and Cary, 1996). The EC concentrations determined by the thermal methods should agree with the optical BC measurements. However, a disagreement

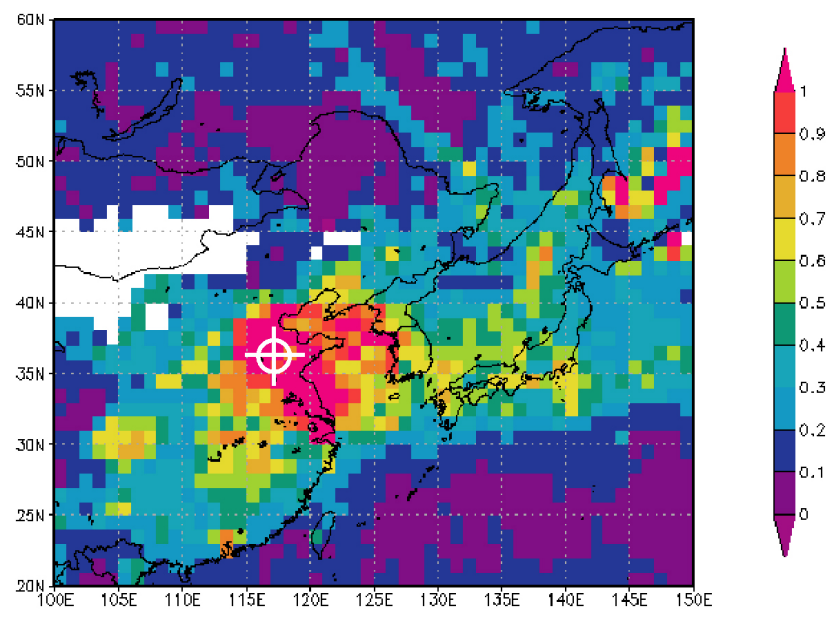

Fig. 1. Location of Mt. Tai $\left(36.26^{\circ} \mathrm{N}, 117.11^{\circ} \mathrm{E}, 1534 \mathrm{~m}\right.$ a.s.l.) shown together with aerosol optical depth at $550 \mathrm{~nm}$ measured by a MODIS sensor on board the Aqua satellite during the campaign period, June 2006, (http://disc1.sci.gsfc.nasa.gov/G3/movas.shtml).

by up to a factor of 4 has been reported (Park et al., 2006; Jeong et al., 2004; Bae et al., 2007; Hitzenberger et al., 2006; Reisinger et al., 2008), depending on the used techniques, sites, and aerosol properties. Although there has been much discussion about the selection of the temperature program and the mass absorption/attenuation coefficient assumed to calculate $\mathrm{BC}$ concentrations from the optical measurements, solid and systematic conclusions have not yet been reached. In this situation, one approach for the better quantification of BC concentrations would be to make measurements using several instruments and examine the differences. Such comprehensive measurements of $\mathrm{BC}$ aerosols have not been performed in China.

We performed an intensive field campaign on the summit of Mount Tai $\left(36.26^{\circ} \mathrm{N}, 117.11^{\circ} \mathrm{E}, 1534 \mathrm{~m}\right.$ a.s.l., Shandong Province of the People's Republic of China), located in the middle of CEC (Fig. 1), in June 2006 (The Mount Tai Experiment 2006, MTX2006) focusing on aerosol and ozone chemistry. The field site is free from local sources but is located at the center of the regionally polluted area over CEC (Fig. 1), providing a regionally-representative data set. One aim of the campaign was to determine $\mathrm{BC}$ concentration levels using multiple instruments to better constrain the emission rate from CEC that currently has large uncertainty. The instruments used were a multi-angle absorption photometer (5012 MAAP, Thermo) (Petzold and Schönlinner, 2004; Petzold et al., 2005), a particle soot absorption photometer (PSAP, Radiance Research) (Bond et al., 1999), and an ECOC semicontinuous analyzer (Sunset Laboratory) (Bae et al., 2004). An Aethalometer (AE-21, Magee Scientific) was also operated for several days during the first part of the campaign. In this paper, the observational results from the four instruments are compared. We found compact correlations but 


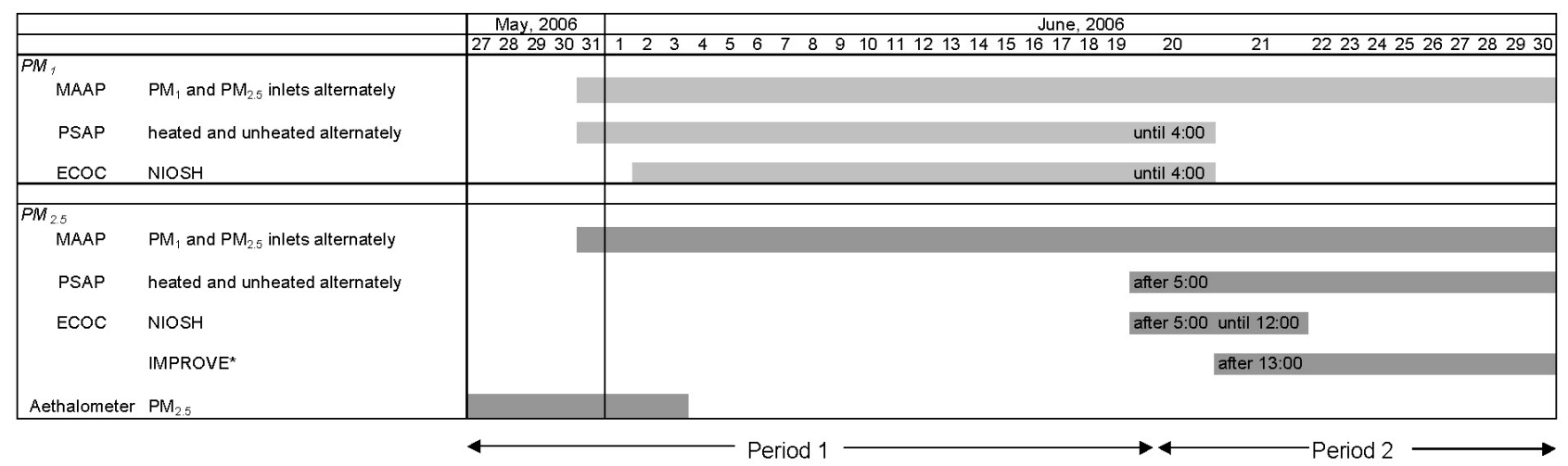

Fig. 2. Operation of the four instruments shown separately for $\mathrm{PM}_{1}$ and $\mathrm{PM}_{2.5}$ measurements.

systematic differences between the mass concentrations derived from these instruments. From the range of the slopes of the linear least-square fittings, we conclude that the black carbon concentrations regionally representative over CEC were measured in a range with a maximum-to-minimum ratio of 1.5 (with one exception). This factor would be small enough to better constrain the emission rate of BC from CEC. We also investigate possible reasons for the optical measurements tending to give higher concentrations than the thermal method.

\section{Experimental}

Figure 2 shows the operation of the MAAP, PSAP, ECOC analyzer, and Aethalometer during the campaign. (The acronyms, full names, principles, operation modes, and detection limits of the instruments are summarized in Appendix A.) Most of the instruments were operated with $\mathrm{PM}_{1}$ (1- $\mu \mathrm{m}$-diameter cutoff) cyclones during the early period (Period 1, before 20 June, 04:00 CST (Chinese Standard Time; $\mathrm{UT}+8 \mathrm{~h})$ ) and with $\mathrm{PM}_{2.5}(2.5-\mu \mathrm{m}$-diameter cutoff) cyclones during the late period (Period 2, after 20 June, 05:00 CST). Thus the following comparisons are made for the two periods separately. For the MAAP instrument, an automated valve switched between the two cyclones (URG-2000-30EHB and URG-2000-30EH, URG Inc.) every $30 \mathrm{~min}$ such that sampling alternated between $\mathrm{PM}_{1}$ and $\mathrm{PM}_{2.5}$. The MAAP instrument calculates absorbance from particles deposited on the filter using measurements of both transmittance and reflectance at two different angles. The absorbance is then converted to the mass concentration of $\mathrm{BC}$ using a fixed mass absorption coefficient at $670 \mathrm{~nm}$ of $6.6 \mathrm{~m}^{2} \mathrm{~g}^{-1}$ as recommended by the manufacturer. The BC concentration derived from the MAAP instrument is hereafter referred to as MAAP_BC. The firmware used during the campaign was version 1.29. It is known that measurements with this firmware version show a leveling-off behavior at high concentrations (ca. $>7 \mu \mathrm{g} \mathrm{m}^{-3}$ ). Thus the raw data from the instrument were empirically corrected using a correction term provided by the manufacturer. The correction was based on a comparison between the MAAP results (using version 1.29) and a reference method (DRI, Thermal-Optical-Reflectance correction, IMPROVE method) at two Japanese sites (Hasegawa et al., unpublished data, 2005). The version after the correction is referred to as version 1.29 corr. The uncertainty in the determined absorbance has been estimated to be $12 \%$ (Petzold and Schönlinner, 2004). The uncertainty in the BC mass concentration, including the uncertainty in the mass absorption coefficient, is estimated to be larger. The minimum detection limit is specified by the manufacturer to be $<0.1 \mu \mathrm{g} \mathrm{m}^{-3}$ with an averaging time of $2 \mathrm{~min}$.

For the PSAP instrument, an automated valve switched between inlet tubes with and without heating at a frequency of $30 \mathrm{~min}$. Only a short portion of a stainless steel tube (o.d. $3 / 8^{\prime \prime}, 21 \mathrm{~cm}$ long) was heated and kept at $400^{\circ} \mathrm{C}$. Considering the sample flow rate of $1.0 \mathrm{~L} \mathrm{~min}^{-1}$, the residence time of the sampled air in the heated portion of the inlet tubing was only $\sim 0.6 \mathrm{~s}$. With heating, volatile compounds of aerosols (nitrates, organics, sulfates) internally or externally mixed with $\mathrm{BC}$ would be evaporated and thus the BC particles without coating, if originally present, would be collected on a filter. Kondo et al. (2006) reported that such heating at $400^{\circ} \mathrm{C}$ removed about $97 \pm 5 \%$ of inorganic $\left(\mathrm{SO}_{4}^{2-}\right.$, $\mathrm{NO}_{3}^{-}, \mathrm{Cl}^{-}$, and $\mathrm{NH}_{4}^{+}$) and organic components as measured by an Aerodyne aerosol mass spectrometer (AMS), while the charring of the organic species is kept to a minimum. It is assumed in this study that this holds for the PSAP instrument. Kondo et al. (2006) have also reported that such heating makes the mass absorption coefficient much more stable even when the degree of the mixing of $\mathrm{BC}$ is changing. A $\mathrm{PM}_{1}$ cyclone (URG-2000-30EHB) was used for the PSAP instrument before 20 June, 04:00 CST, but it was replaced by a $\mathrm{PM}_{2.5}$ cyclone (URG-2000-30EH) on 20 June, 05:00 CST. For both heated and unheated measurements, a single mass absorption coefficient $10 \mathrm{~m}^{2} \mathrm{~g}^{-1}$ at $565 \mathrm{~nm}$ was employed to convert the light attenuation to the $\mathrm{BC}$ mass concentration as recommended by the manufacturer. The filter was manually changed and only data with transmittance higher than 
Table 1. Temperature Programs used for the ECOC Analyzer during the Campaign.

\begin{tabular}{cccccc}
\hline & & \multicolumn{2}{c}{ NIOSH $^{\mathrm{a}}$} & \multicolumn{2}{c}{ IMPROVE*b $^{* \mathrm{~b}}$} \\
\hline Step & Atmosphere & $\begin{array}{c}\text { Temperature } \\
\left({ }^{\circ} \mathrm{C}\right)\end{array}$ & $\begin{array}{c}\text { Hold times } \\
(\mathrm{s})\end{array}$ & $\begin{array}{c}\text { Temperature } \\
\left({ }^{\circ} \mathrm{C}\right)\end{array}$ & $\begin{array}{c}\text { Hold times } \\
(\mathrm{s})\end{array}$ \\
\hline 1 & $\mathrm{He}$ & - & $30[10]^{\mathrm{c}}$ & - & 10 \\
2 & $\mathrm{He}$ & 600 & 80 & 350 & 90 \\
3 & $\mathrm{He}$ & 840 & $90[70]^{\mathrm{c}}$ & 550 & 120 \\
4 & $\mathrm{He}$ & Oven off & 55 & Oven off & 0 \\
5 & $\mathrm{He}: \mathrm{O}_{2}$ & 550 & 30 & 550 & 75 \\
6 & $\mathrm{He}: \mathrm{O}_{2}$ & 850 & 110 & 700 & 75 \\
7 & $\mathrm{He}: \mathrm{O}_{2}$ & - & - & 850 & 90 \\
8 & $\mathrm{He}: \mathrm{O}_{2}$ & Oven off & $85[0]^{\mathrm{c}}$ & Oven off & 30 \\
9 & $\mathrm{CH}_{4}$ & - & $120[100]^{\mathrm{c}}$ & - & 120 \\
\hline
\end{tabular}

\footnotetext{
a NIOSH program was employed before 21 June, 12:00 CST.

b IMPROVE* program was employed after 21 June, 13:00 CST.

c Analysis time was shortened between 18 June, 15:00 and 20 June, 05:00 CST.
}

0.5 were used for analysis. The uncertainty in the determined light attenuation is estimated to be $\pm 15 \%$ in the heated mode, while the uncertainty in the $\mathrm{BC}$ mass concentration is estimated to be larger. A detection limit of $1.8 \times 10^{-6} \mathrm{~m}^{-1}$ (signal-to-noise ratio of 2) with an averaging time of $1 \mathrm{~min}$ (Li et al., 2007) corresponded to a detection limit of heated PSAP_BC of $\sim 0.2 \mu \mathrm{g} \mathrm{m}^{-3}$, assuming a mass absorption coefficient of $10 \mathrm{~m}^{2} \mathrm{~g}^{-1}$. In the following discussion the measurements made by the PSAP instrument are referred to as heated PSAP_BC and unheated PSAP_BC.

The ECOC analyzer from Sunset Laboratory was operated with the NIOSH temperature program before 21 June, 12:00 CST and with a program similar to that proposed by the IMPROVE after 21 June, 13:00 CST (herein we refer to it as the "IMPROVE*" program, where the temperature is raised only to $550^{\circ} \mathrm{C}$ under a $\mathrm{He}$ atmosphere similarly to the IMPROVE program but the analysis time was shorter than the original recommendation). The specific temperaturerise programs employed during the campaign are listed in Table 1. We employed transmittance for optical correction, as opposed to reflectance which is used in the normal IMPROVE method. The sampling line was equipped with a $\mathrm{PM}_{1}$ cyclone before 20 June, 04:00 CST, and a $\mathrm{PM}_{2.5}$ cyclone after 20 June, 05:00 CST. Gas-phase organic carbon species were removed by a denuder (Sunset Laboratory). An hourly measurement cycle was employed; the sampling period (at a flow rate of $\sim 8 \mathrm{~L} \mathrm{~min}^{-1}$ ) was 40 or $42 \mathrm{~min}$, followed by an analysis period of $\sim 15 \mathrm{~min}$. The ECOC analyzer was calibrated with a known amount of sucrose $(42.1 \mu \mathrm{gC})$. As mentioned earlier, the ECOC analyzer is equipped to measure the laser transmittance at $660 \mathrm{~nm}$ through the filter to determine the split point between OC and EC during the thermal analysis. The change in the transmittance during the sample collection was also used to determine BC concentrations optically. The BC mass loading (in $\mu \mathrm{g} \mathrm{cm}^{-2}$ ) on the filter was empirically determined by $2.25 \times \mathrm{ABS}+0.75 \times(\mathrm{ABS})^{2}$, where ABS (absorbance) is determined from the temporal decrease in the laser transmittance during sample collection. The mass loading was then converted to concentration using the filter area and sample volume. The thermal and optical measurements based on the ECOC analyzer are hereafter referred to as EC and opt-EC, respectively. The uncertainty in the total carbon ( $\mathrm{TC}=\mathrm{EC}+\mathrm{OC}$ ) concentrations was estimated to be $\pm 25 \%$, owing to the uncertainties in the sample flow rate and calibrations during the campaign. Unfortunately, the operation condition of the instrument during the campaign was not very good; the measurements of the laser transmittance and flow rate were frequently affected by electric noise. Please note that the uncertainty in the split point that would depend on the selection of the temperature program will produce additional uncertainty in EC and OC. The following analysis (Sect. 3.2) suggests a $31 \%$ uncertainty arising from the selection of the temperature program. The detection limit of EC with a sampling time period of $40 \mathrm{~min}$ was estimated to be $<0.4 \mu \mathrm{gC} \mathrm{m}^{-3}$.

The Aethalometer measured light attenuation by aerosol particles deposited on a filter at two wavelengths, $880 \mathrm{~nm}$ and $370 \mathrm{~nm}$. In this paper, measurements at $880 \mathrm{~nm}$ were used. A mass absorption cross section of $16.6 \mathrm{~m}^{2} \mathrm{~g}^{-1}$ was used to convert the observed light attenuation to the mass concentration of BC. Aerosol particles were sampled through a $1 / 4^{\prime \prime}$ ID Tygon tube ( $2 \mathrm{~m}$ long) to the Aethalometer. A PM 2.5 cyclone (BGI SCC 1.828-5 Lpm) was employed in the sampling line with a flow rate of $5 \mathrm{~L} \mathrm{~min}^{-1}$. A typical noise level is $<0.1 \mu \mathrm{gC} \mathrm{m}^{-3}$ on a 5 -min basis. 

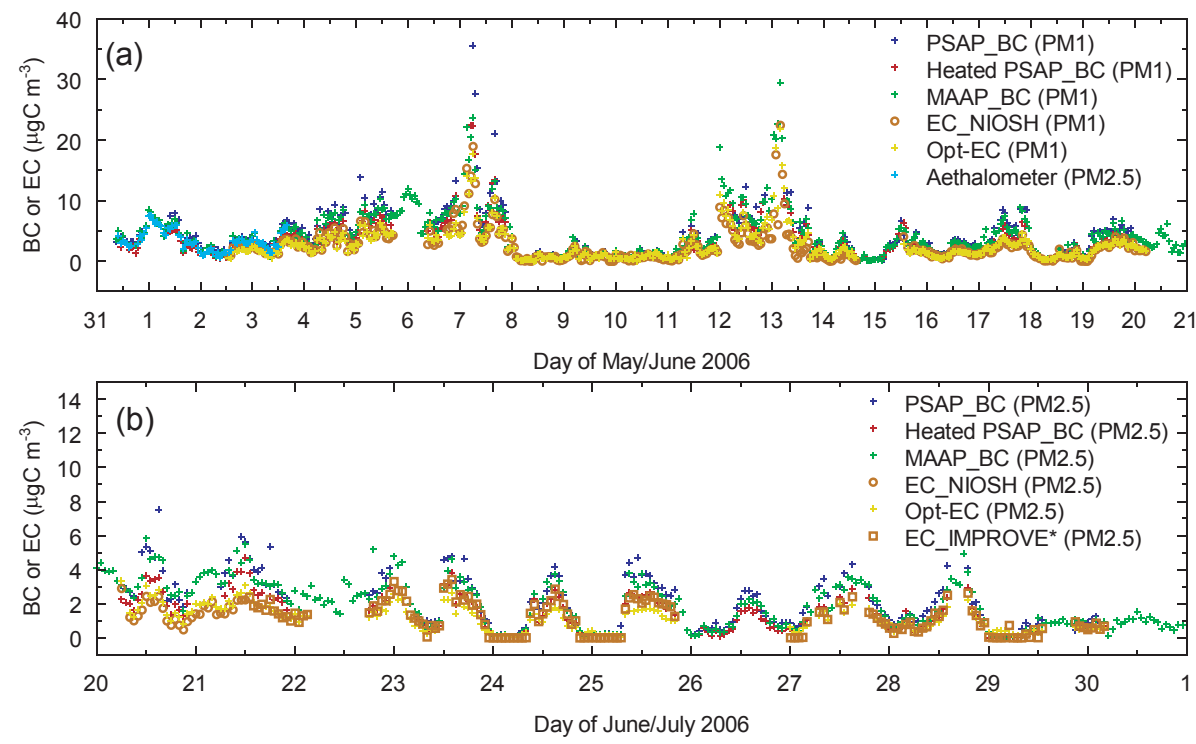

Fig. 3. Temporal variations in $\mathrm{BC}$ concentrations measured with four instruments. Panel (a): for the period between 31 May and 20 June (Period 1), when measurements with $\mathrm{PM}_{1}$ cyclones are mainly performed, with an exception that Aethalometer data for $\mathrm{PM}_{2.5}$ are included. Panel (b): for the period between 20 and 30 June (Period 2), for which all plotted quantities are observed with $\mathrm{PM}_{2.5}$ cyclones.

The assumed mass absorption cross sections for the optical instruments are the ones empirically determined for particles under certain conditions. The conditions are not necessarily identical for all instruments. Therefore, it is not obvious that they are directly applicable for measurement of the black carbon particles at the top of Mt. Tai. Cross sections, depending on their size, shape, and the mixing state of the particles theoretically, should have uncertainties of a factor of $\sim 2$. In this study, we first use the cross sections recommended by the manufacturers for simplicity and then discuss systematic differences in the $\mathrm{BC}$ concentrations derived from the instruments.

\section{Results and discussions}

The hourly data from the MAAP, PSAP, ECOC, and Aethalometer instruments are plotted as a time series in Fig. 3a and $\mathrm{b}$ for Periods 1 and 2, respectively. The hourly $\mathrm{BC}$ concentration $\left(\mathrm{PM}_{2.5}\right)$ as measured by the MAAP instrument (shown only for Period 2) ranged from -0.1 to $+40.8 \mu \mathrm{gC} \mathrm{m}^{-3}$ with an average of $3.7 \mu \mathrm{gC} \mathrm{m}^{-3}$. Two episodes with high $\mathrm{BC}$ concentrations are easily recognized for 5-7 June and 11-13 June. The high concentrations likely stem from significant open biomass burning of crop residues (winter wheat) over the North China Plain as discussed elsewhere (Li et al., 2008; Akimoto et al., 2008). It should be noted in the following discussion that the high concentration episodes occurred during Period 1, when the NIOSH program was employed for the ECOC analyzer. We found a regular diurnal variation pattern with a daytime maximum and nighttime minimum in Period 2 (Fig. 3b). The pattern is due

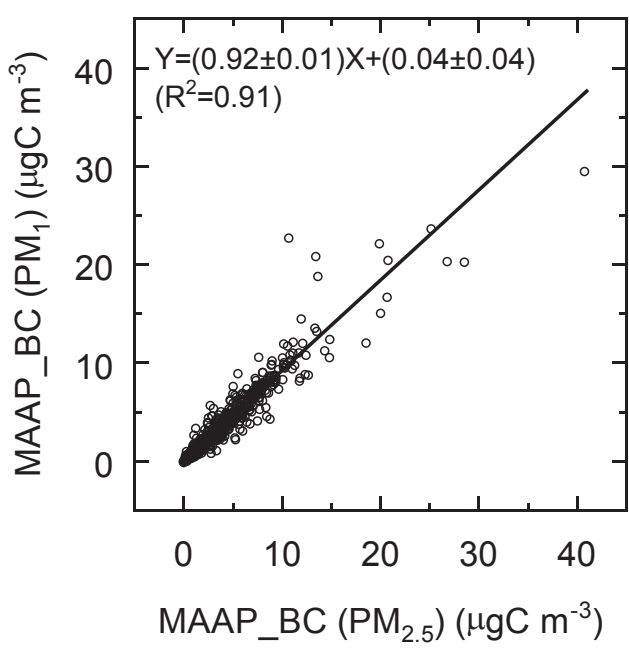

Fig. 4. Comparison between $B C$ measurements made by a MAAP instrument employing $\mathrm{PM}_{1}$ and $\mathrm{PM}_{2.5}$ cyclones. The sequential $\mathrm{PM}_{2.5}$ and $\mathrm{PM}_{1}$ measurements within an hour ( $30 \mathrm{~min}$ for each) were regarded as a pair of hourly data.

to polluted air mass being transported to the mountain top during the daytime, which is associated with the buildup of the planetary boundary layer. During the night, on the other hand, the observed air mass is isolated from the sources. A similar diurnal pattern has been previously observed for $\mathrm{CO}$ and ozone at the site (Gao et al., 2005). In the following subsections, we separately discuss various aspects of the comparisons. 

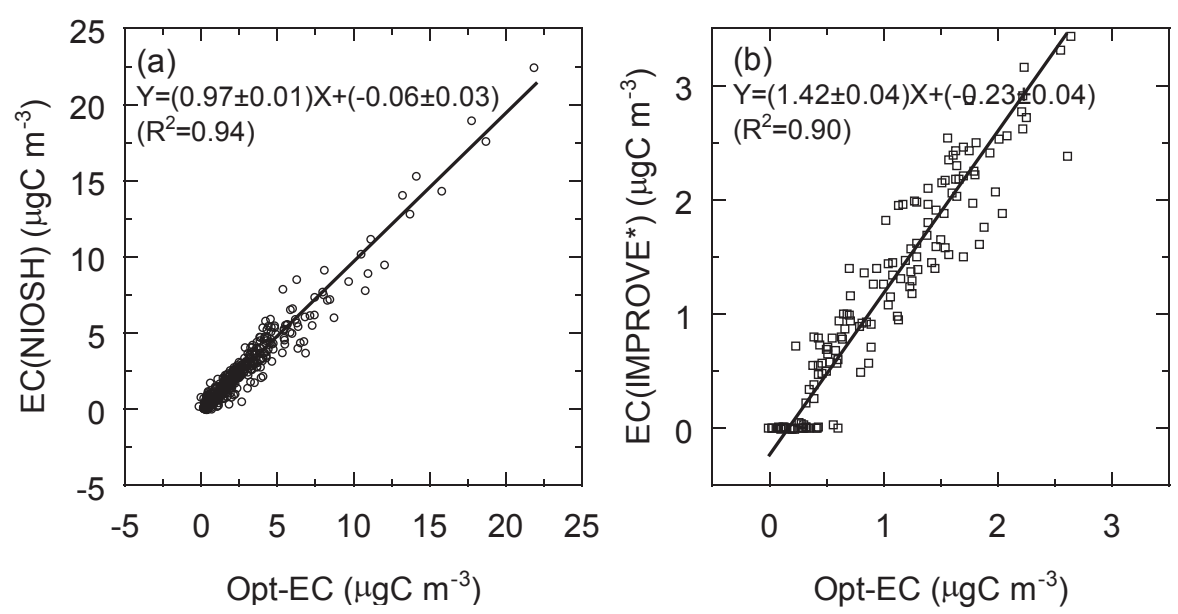

Fig. 5. Relationship between opt-EC with thermal EC measurements employing (a) NIOSH and (b) IMPROVE* temperature programs.

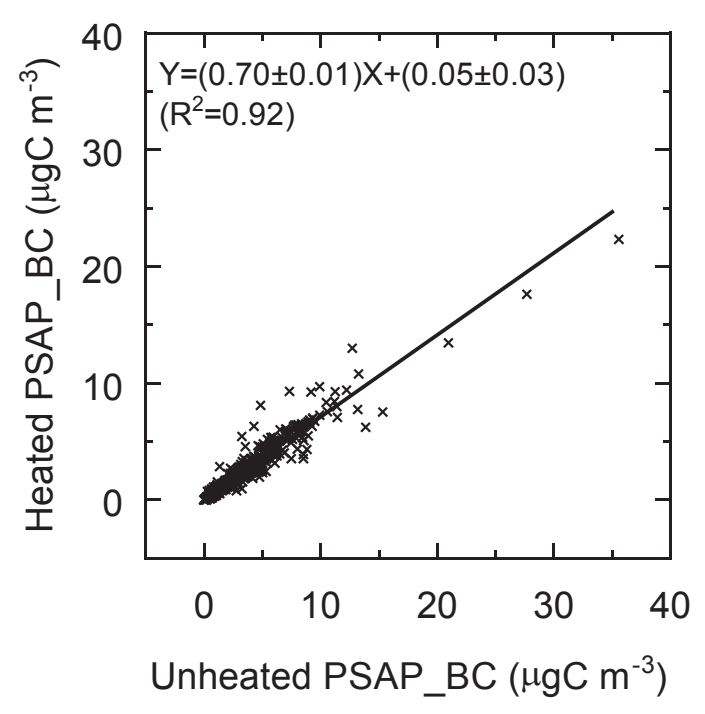

Fig. 6. Comparison of $\mathrm{BC}$ concentrations measured by a PSAP instrument with heated and unheated inlet tubes.

\section{$3.1 \quad \mathrm{PM}_{1}$ vs. $\mathrm{PM}_{2.5}$ (MAAP)}

Figure 4 shows a comparison between $\mathrm{BC}$ concentrations measured by a MAAP instrument employing $\mathrm{PM}_{1}$ and $\mathrm{PM}_{2.5}$ cyclones. The sequential $\mathrm{PM}_{2.5}$ and $\mathrm{PM}_{1}$ measurements within an hour (30 min for each) were regarded as a pair of hourly data. Although the measurement time periods did not exactly match, a tight correlation was found between them. This is because the temporal variation in the $\mathrm{BC}$ concentration was dominated by low-frequency components. The slope was $0.92 \pm 0.01$, suggesting that $92 \%$ of $\mathrm{BC}$ is present in the submicron fraction of aerosol particles.
3.2 Opt-EC vs. EC: estimating the difference between NIOSH and IMPROVE* temperature programs

The EC measurements with different temperature protocols, NIOSH and IMPROVE*, are plotted against opt-EC in Fig. 5a and b. Tight correlations are found for both cases, implying that the ECOC analyzer measured the same component of aerosol particles by the two different techniques (i.e., optical and thermal techniques). The slopes of the bivariate linear regression analyses were $0.97 \pm 0.01$ and $1.42 \pm 0.04$, respectively. It should be noted the concentration ranges for the two figures are different: Fig. 5a includes $\mathrm{PM}_{1}$ data before 20 June, 04:00 CST (with high values during biomass burning episodes) and $\mathrm{PM}_{2.5}$ data between 20 June, 05:00 CST and 21 June, 12:00 CST, while Fig. 5b contains measurements of $\mathrm{PM}_{2.5}$ after 21 June 13:00 CST (with lower values). When opt-EC data lower than $2.64 \mu \mathrm{gC} \mathrm{m}^{-3}$ were selected, the slope of the regression line between optEC and NIOSH-EC was $1.08 \pm 0.03$. This analysis suggests IMPROVE*-EC is systematically higher than NIOSH-EC by $31 \%$ on average, although we cannot eliminate the possibility that the difference arose from the different aerosol properties in the two periods. The magnitude of the difference is slightly larger than that reported for Tokyo of $21 \%$ (Kondo et al., 2006). Because the NIOSH protocol utilizes higher temperatures under a $\mathrm{He}$ atmosphere, EC might have started combustion and been counted as OC under the NIOSH program. Conversely, OC that can be evaporated only at higher temperature might have been included as EC under the IMPROVE* program.

\subsection{Heated and unheated PSAP}

Figure 6 shows a comparison between BC concentrations measured by a PSAP instrument with heated and unheated inlet tubes. Similar to the case above (Sect. 3.1), the two 
measurements were only made alternately by switching a 3way valve every $30 \mathrm{~min}$. Both the data for Periods 1 and 2 are included in Fig. 6. The slope of a regression line is $0.70 \pm 0.01\left(R^{2}=0.92\right)$, suggesting that using the heated inlet tube resulted in BC concentration readings $30 \%$ lower than for the case using the unheated tube when an identical mass absorption coefficient $\left(10 \mathrm{~m}^{2} \mathrm{~g}^{-1}\right)$ was used. This indicates the mass absorption (attenuation) coefficient for the unheated tube is $30 \%$ higher than that for the heated tube, on average. Scattering by externally mixed particles deposited on the filter might have been counted as absorption in the unheated mode. In addition, internal mixing of transparent components might have changed the absorbance. As discussed by Kanaya et al. (2008), the $\mathrm{NO}_{\mathrm{x}} / \mathrm{NO}_{\mathrm{y}}$ ratio was only $0.18 \pm 0.10$ on average during the campaign, suggesting the observed air mass is normally aged. The air mass age for a $\mathrm{NO}_{\mathrm{x}} / \mathrm{NO}_{\mathrm{y}}$ ratio of 0.18 was roughly estimated to be 35 or $20 \mathrm{~h}$, using modelderived $\mathrm{OH}$ concentrations of $1.8 \times 10^{6}$ or $3.1 \times 10^{6}$ radicals $\mathrm{cm}^{-3}$ as 24-h or daytime 12-h averages for this campaign period (Kanaya et al., 2008), respectively. In this calculation, we neglected conversion between $\mathrm{NO}_{\mathrm{x}}$ and peroxy acetyl nitrate (PAN), continuous input of $\mathrm{NO}_{\mathrm{x}}$ during the aging process, and removal of $\mathrm{NO}_{\mathrm{y}}$ during transport. During the aging process, $\mathrm{BC}$ particles might have been coated by transparent components (e.g., OC), which could enhance absorption by the lensing effect. Bond et al. (2006) suggested that absorption by aged particles can be 1.5 times greater than that of fresh particles due to the coating.

\subsection{Comparisons across instruments}

Data from the Aethalometer $\left(\mathrm{PM}_{2.5}\right)$ can be compared only with the data from the MAAP operated with a $\mathrm{PM}_{2.5}$ inlet in the same period. Figure 7 shows a tight correlation between them, with a slope of the regression line of $0.88 \pm 0.03$ $\left(R^{2}=0.92\right)$. A good agreement was obtained, although coincident observations were made by the two instruments only for 4 days.

Correlations and least-square fittings for each pair among EC (NIOSH), opt-EC, heated_PSAP, and MAAP for Period 1 are shown in Fig. 8a. We found strong correlations $\left(R^{2}>0.88\right)$ for all the pairs. The slopes and intercept values of regression lines ranged from 1.03 to 1.54 and from -0.08 to $+0.51 \mu \mathrm{gC} \mathrm{m}^{-3}$, respectively, suggesting general agreement among the three instruments. From the slope values, we can infer the general magnitude relationship as EC $\left(\mathrm{PM}_{1}, \mathrm{NIOSH}\right) \sim$ opt-EC $\left(\mathrm{PM}_{1}\right)<$ heated PSAP_BC $\left(\mathrm{PM}_{1}\right)$ $\sim$ MAAP_BC $\left(\mathrm{PM}_{1}\right)$. The largest discrepancy was found between EC (PM $1, \mathrm{NIOSH})$ and MAAP_BC $\left(\mathrm{PM}_{1}\right)$, with a slope of 1.54 .

Similar analyses for Period 2 (Fig. 8b), using the EC data with the IMPROVE* temperature rise protocol, yielded similar ranges of the slope (1.07-1.46) and intercept $\left(-0.23-+0.10 \mu \mathrm{gC} \mathrm{m}^{-3}\right)$ with high $R^{2}$ values $(0.88-$ 0.94), except that MAAP_BC was significantly higher

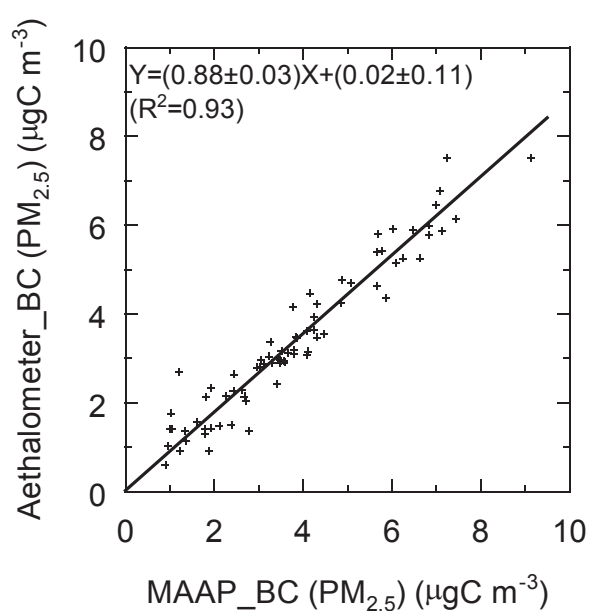

Fig. 7. Comparison of $\mathrm{BC}$ concentrations from the Aethalometer $\left(\mathrm{PM}_{2.5}\right)$ and MAAP $\left(\mathrm{PM}_{2.5}\right)$.

than opt-BC (MAAP_BC $\left(\mathrm{PM}_{2.5}\right)=1.95 \times($ opt-EC PM 2.5$)-$ $0.16 \mu \mathrm{gC} \mathrm{m}^{-3}$, with $R^{2}=0.91$ ). A similar scatter plot between the MAAP_BC and opt-EC for Period 1 for a limited data set satisfying [opt-EC] $<2.64 \mu \mathrm{gC} \mathrm{m}^{-3}$ (similar to the opt-EC range during Period 2) also yielded a high slope value (2.13), suggesting opt-EC tends to give low values in the low concentration range. The MAAP vs. EC (IMPROVE*) plot for Period 2 yielded a slope of $1.45 \pm 0.04$, slightly lower than $1.54 \pm 0.03$ for the MAAP vs. EC (NIOSH) plot for Period 1. As studied in Sect. 3.2, the IMPROVE* temperature protocol tends to give higher concentrations than does NIOSH, showing a slightly better agreement with the MAAP data.

From these analyses that yielded the ratios of the highest to lowest concentrations of $\sim 2$ at worst (generally $\leq 1.5$ ), we conclude that while the differences among the BC concentrations from the four different instruments were significant, the range was still sufficiently narrow to better constrain the BC emission rate from CEC (with uncertainties similar to those of all China, a factor of 3.9 (Bond et al., 2004) and a factor of 34 (Streets et al., 2003) as noted in the Introduction), even when the model results are associated with an uncertainty of a factor of 1.5. Yamaji et al. (2008) will simulate BC concentrations using a regional-scale chemical transport model and compare them with the observations, testing the $\mathrm{BC}$ emission rate from CEC.

The deviations from unity of the slope values in Figs. 7 and 8 could be at least partially attributable to wrongly assumed absorption cross sections for the optical instruments. But it is not possible to re-determine the cross sections because none of the instruments can be regarded as standard. Nonetheless, it should be noted that there is a common tendency that PSAP and MAAP need to have larger cross sections than originally assumed to reduce the $\mathrm{BC}$ values down to the levels of $\mathrm{EC}$ (or that the EC values are consistently underestimated for some reasons). This tendency is studied in more detail in the next section. 

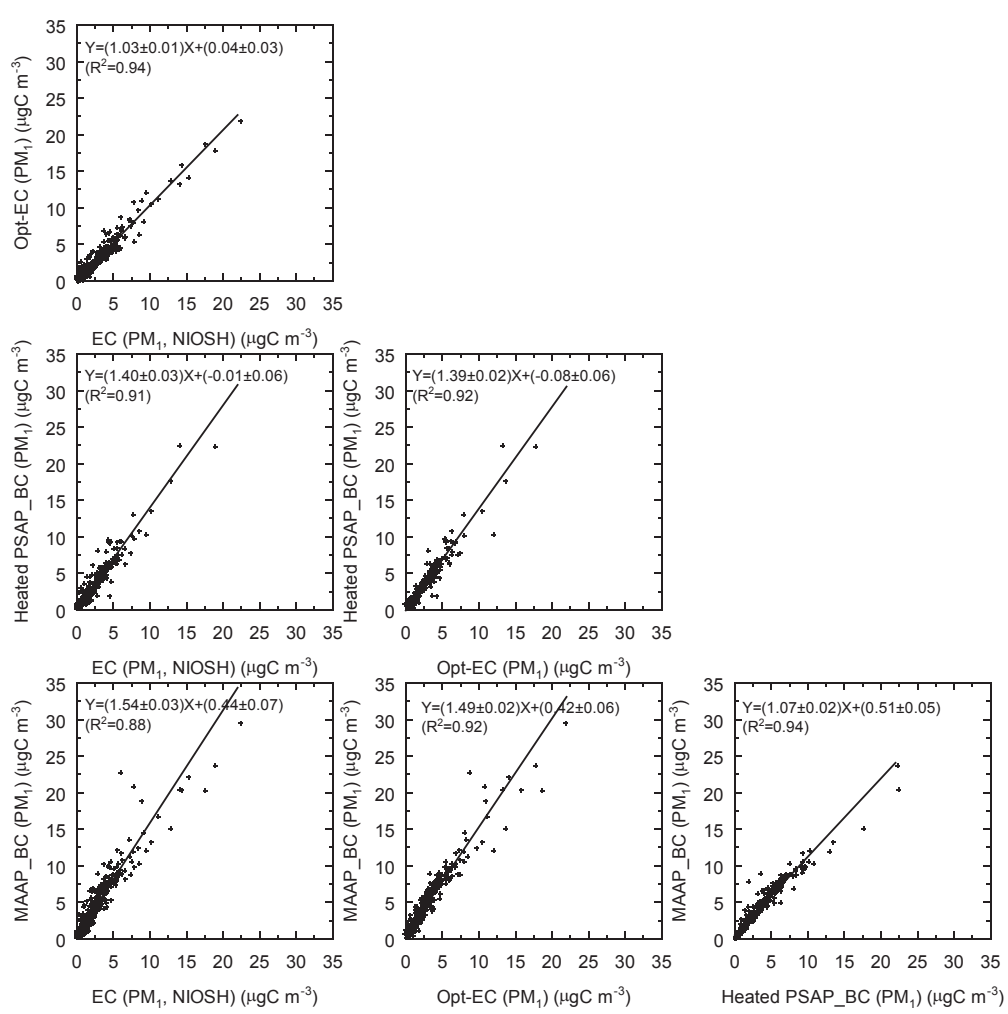

Fig. 8a. Correlations and least-square fittings for each pair among EC (NIOSH), opt-EC, heated PSAP_BC, and MAAP_BC for Period 1.
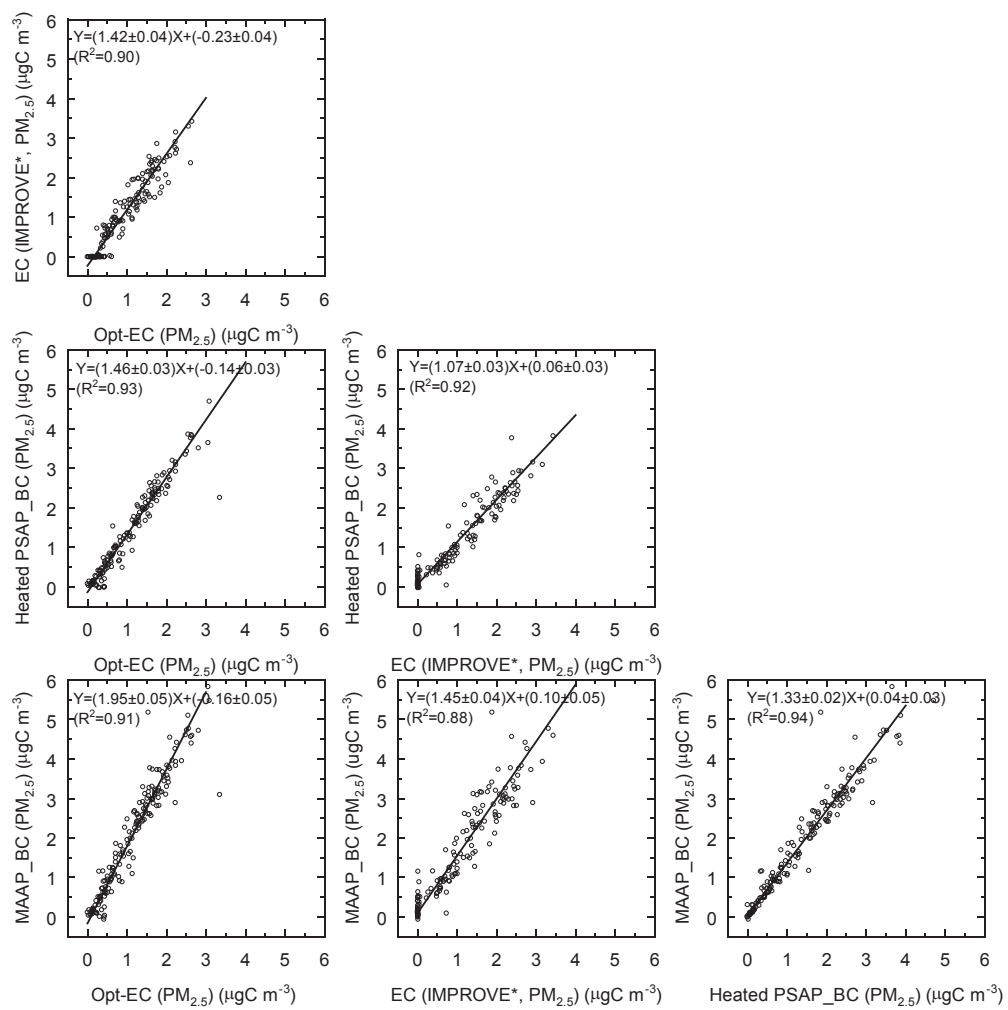

Fig. 8b. Correlations and least-square fittings for each pair among EC (IMPROVE*), opt-EC, heated PSAP_BC, and MAAP_BC for Period 2. 

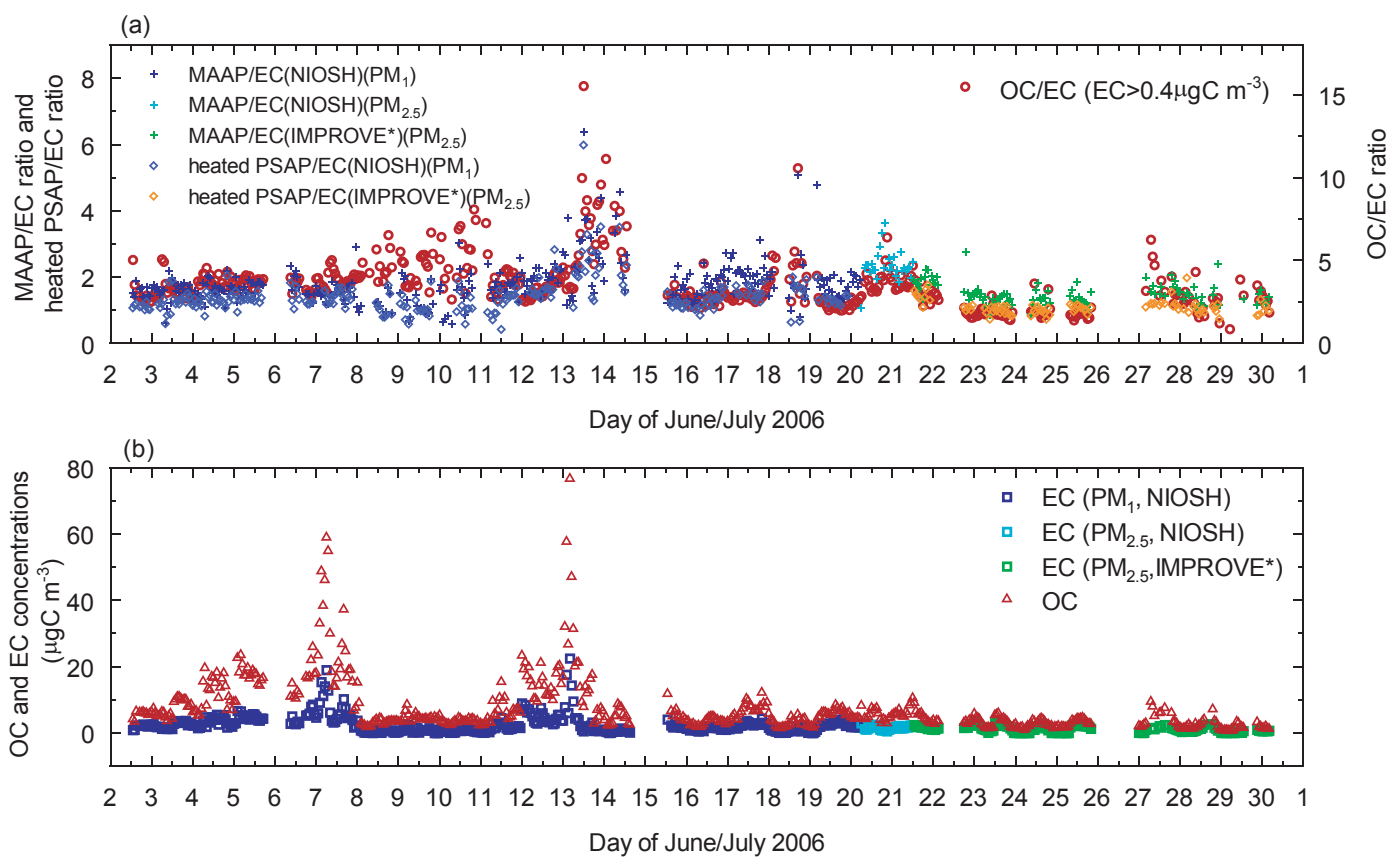

Fig. 9. (a) Temporal variations in the MAAP_BC/EC ratio and heated PSAP_BC/EC ratio (left axis) compared with temporal variations in the OC/EC ratio (red, right axis). (b) Time series of OC and EC mass concentrations observed by the ECOC analyzer.

3.5 Analysis of differences between optical BC and thermal EC concentrations

Figure 9a illustrates that the MAAP_BC/EC and heated PSAP_BC/EC ratios show temporal variations similar to that of the OC/EC ratio determined by the ECOC analyzer. During Period 1, the correlation coefficients were $0.59(n=330)$ and 0.68 ( $n=253)$, respectively. On the afternoon of 13 June for example, the MAAP_BC/EC and heated PSAP_BC/EC ratios had elevated values together with high OC/EC ratios. It should be noted this case does not correspond to the intense biomass burning event with high OC and EC concentrations; these maxima in the $\mathrm{BC} / \mathrm{EC}$ ratios occurred several hours after the event (see Fig. 9b).

There are two possible explanations. First, the optical methods might have overestimated the $\mathrm{BC}$ concentrations when the OC is more abundant. The OC might have coated $\mathrm{BC}$ particles and enhanced absorption by the lensing effect. The MAAP instrument, in principle, measures the reflected light at two different angles to cancel the scattering effect of the deposited aerosols. However, the lensing effect is not likely to be taken into account in principle. For the PSAP instrument, the heating temperature $\left(400^{\circ} \mathrm{C}\right)$ might not have been high enough for all the OC to be volatilized. Secondly, the ECOC analyzer might have underestimated EC concentrations when $\mathrm{OC}$ was present at relatively high concentrations. It is possible that the determined split point between $\mathrm{OC}$ and $\mathrm{EC}$ was too late, resulting in an underestimation of $\mathrm{EC}$ and overestimation of OC.
For the enhanced BC/EC event on the afternoon of 13 June, the raw thermogram from the ECOC analyzer shows the presence of an $\mathrm{OC}$ fraction volatilized only at a high temperature of more than $400^{\circ} \mathrm{C}$ (Fig. 10a, between ca. 100 and $250 \mathrm{~s})$. For this case, the $\mathrm{BC}$ concentrations from both the MAAP and heated PSAP instruments were 2.5 times the $\mathrm{EC}$ concentration and the OC/EC ratio was 7.1 ([OC]=12.9, $\left.[\mathrm{EC}]=1.8 \mu \mathrm{gC} \mathrm{m}^{-3}\right)$. This fraction of OC might not have been vaporized but deposited on the filter even in the heated mode of the PSAP measurement, leading to an overestimation of the $\mathrm{BC}$ concentration by enhancing the absorption, although heating was done in air (containing oxygen) for the PSAP instrument as opposed to pure He for the ECOC analyzer. On the other hand, if OC and EC were split at an earlier point, the agreement between the optical BCs and EC should have been improved. When a fraction of OC vaporized only at high temperature is present, the $\mathrm{EC}$ and $\mathrm{OC}$ concentrations might be sensitive to the determination of the split point. It is also possible that the pyrolyzed fraction of OC becomes more important when the OC/EC ratio is high and subsequently the uncertain determination of the split point between the pyrolyzed carbon and the original EC might have affected the $\mathrm{BC} / \mathrm{EC}$ ratios.

A contrasting case is that of 16:00 CST on 16 June, when OC mainly consisted of species volatilized at lower temperatures (Fig. 10b). The heated PSAP_BC was in good agreement with EC (heated PSAP_BC/EC ratio=1.02) and the MAAP_BC was higher than EC only by a factor of 1.24. The OC/EC ratio was 2.4 ([OC] $=4.9$, $[\mathrm{EC}]=2.0 \mu \mathrm{gC} \mathrm{m}^{-3}$ ). We were unable to conduct a more detailed analysis of the 

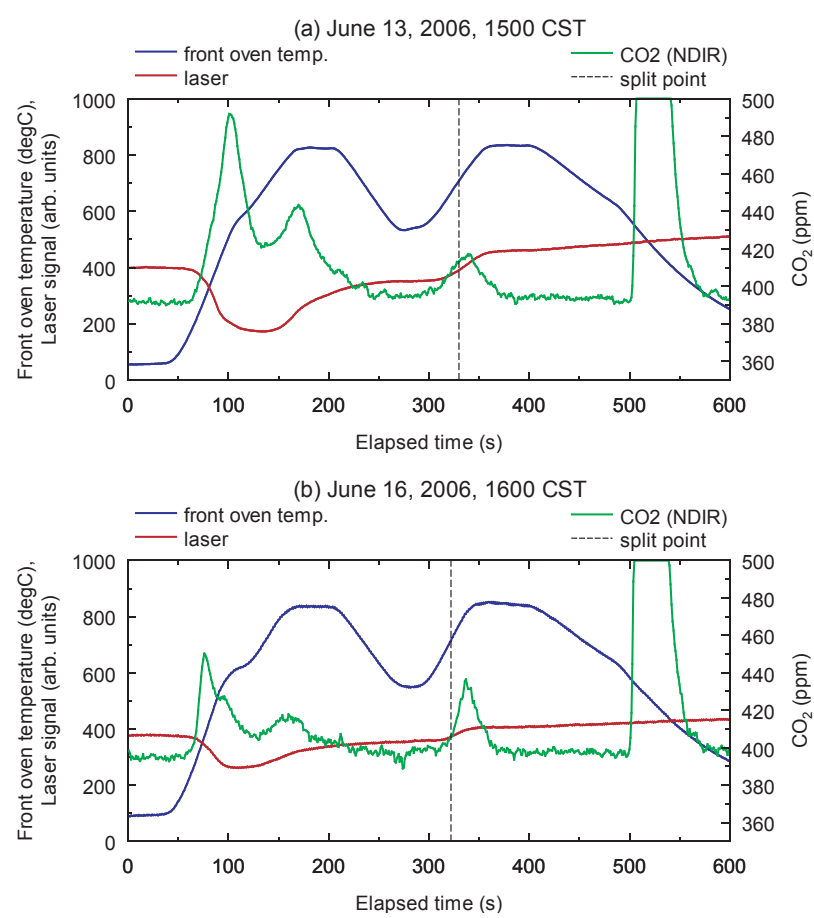

Fig. 10. Thermograms of the ECOC analysis on (a) 13 June 2006, 15:00 CST and (b) 16 June 2006, 16:00 CST. The analysis was made using the NIOSH protocol, under a He atmosphere before $255 \mathrm{~s}$ and an $\mathrm{O}_{2} / \mathrm{He}$ atmosphere after that. The large peak after $500 \mathrm{~s}$ is for calibration.

dependence of the $\mathrm{BC} / \mathrm{EC}$ ratios on the volatility of OC during the campaign, because the time period of thermal analysis was too short to subcategorize OC by volatility and quantify the subcategories individually.

In Fig. 9a, we see the MAAP_BC/EC ratio had a similar co-variation with the OC/EC ratio in Period 2 (21-30 June), for which the IMPROVE* temperature rise program was employed. The qualitative relationship between the MAAP_BC/EC ratio and the OC/EC ratio was basically unaltered by the selection of the temperature program. This may support the first possibility that the optical instruments overestimated the $\mathrm{BC}$ concentrations rather than the second possibility that the thermal EC measurement was underestimated. However, we cannot eliminate the second possibility because using the transmittance (not reflectance) in determining the split point could be more important than the selection of the temperature program for the late split point. The MAAP_BC/EC ratio also showed weak positive correlations $(R=0.54,0.49$, and 0.55$)$ with nitrate $\left(\mathrm{PM}_{1}\right) / \mathrm{EC}$ $\left(\mathrm{PM}_{1}, \mathrm{NIOSH}\right)$, sulfate $\left(\mathrm{PM}_{1}\right) / \mathrm{EC}\left(\mathrm{PM}_{1}, \mathrm{NIOSH}\right)$ and ammonium $\left(\mathrm{PM}_{1}\right) / \mathrm{EC}\left(\mathrm{PM}_{1}, \mathrm{NIOSH}\right)$ ratios, suggesting that these species might also have enhanced absorption measured by the MAAP instrument owing to their coatings. However, the analysis was less reliable because of the limited number of aerosol filter samples $(n=21)$.

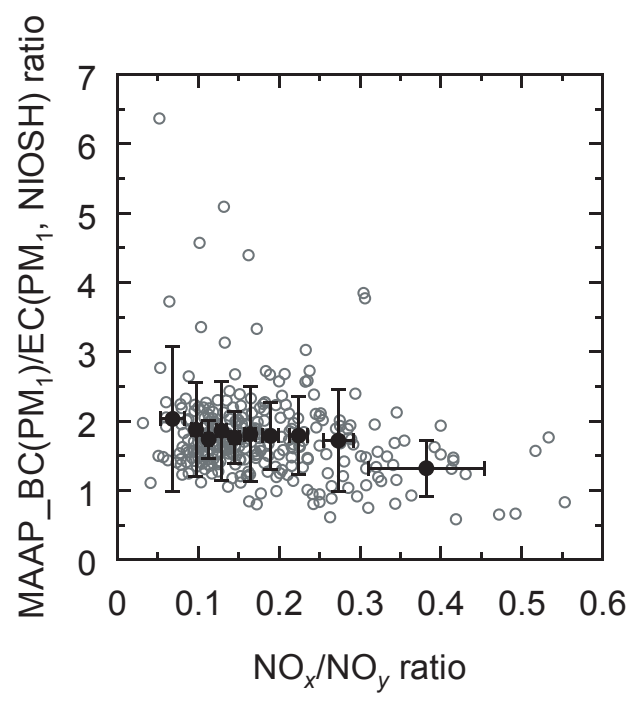

Fig. 11. Relationship between the MAAP_BC to EC ratio and the $\mathrm{NO}_{\mathrm{x}} / \mathrm{NO}_{\mathrm{y}}$ ratio. Gray circles: hourly data; solid circles: data binned by $\mathrm{NO}_{\mathrm{x}} / \mathrm{NO}_{\mathrm{y}}$ ratio.

Figure 11 shows the enhanced MAAP_BC/EC ratios occurred only for low $\mathrm{NO}_{\mathrm{x}} / \mathrm{NO}_{\mathrm{y}}$ ratios, implying that aging is related to large MAAP_BC/EC ratios. Given that the tendency for underestimation of EC is not straightforwardly explained in terms of aging, it is more reasonable to conclude that the $\mathrm{BC}$ particles are coated by transparent materials after aging and that the high MAAP_BC/EC ratios are attributable to the overestimation by the optical instruments owing to the lensing effect induced by the coating. Moteki et al. (2007) and Shiraiwa et al. (2007) illustrated that the fraction of thickly coated black carbon particles increased on a time scale of $12 \mathrm{~h}$ in urban plumes from Japan. In the New England Air Quality Study field campaign in summer 2002, Kleinman et al. (2007) showed that the ratio of BC (optically measured with a PSAP instrument) to $\mathrm{CO}$ concentrations increased by a factor of 2.4 in the air masses in which the $\mathrm{NO}_{\mathrm{x}} / \mathrm{NO}_{\mathrm{y}}$ ratio has decreased to 0.1 , and attributed it to the increase in the mass absorption efficiency with age that could be explained by the deposition of nonabsorbing secondary aerosol and its lensing effect. Slowik et al. (2007) suggested from their laboratory studies that the reading of the MAAP instrument can be increased by $20 \%$ by a $60 \mathrm{~nm}$ anthracene coating.

Jeong et al. (2004) indicated that the Aethalometer overestimated $\mathrm{BC}$ by factors of 3.3 and 2.7 in comparison to EC concentrations $\left(\mathrm{PM}_{2.5}\right)$ measured with a semicontinuous Sunset Laboratory ECOC analyzer in Rochester and Philadelphia in the United States. The tendency that the optical measurements resulted in higher BC concentrations is in accordance with the results of this study. However, they observed a lower factor (0.35) during a Canadian 
Table A1. Acronyms, full names, principles, operation modes, and detection limits of the instruments used in this study.

\begin{tabular}{|c|c|c|c|c|c|}
\hline Acronym & Instrument full name & Model & Principle & Operation modes & Detection limit \\
\hline MAAP & $\begin{array}{l}\text { Multi-Angle } \\
\text { Absorption Photometer }\end{array}$ & 5012MAAP, Thermo & $\begin{array}{l}\text { Transmittance and } \\
\text { reflectance } \\
\text { at two different angles }\end{array}$ & $\mathrm{PM}_{1}$ and $\mathrm{PM}_{2.5}$ & $<0.1 \mu \mathrm{g} \mathrm{m}^{-3}(2 \mathrm{~min})$ \\
\hline PSAP & $\begin{array}{l}\text { Particle Soot } \\
\text { Absorption Photometer }\end{array}$ & PSAP, Radiance Research & $\begin{array}{l}\text { Transmittance } \\
\text { (attenuation) }\end{array}$ & $\begin{array}{l}\text { Unheated and } \\
\text { heated inlet }\end{array}$ & $\sim 0.2 \mu \mathrm{g} \mathrm{m}^{-3}(1 \mathrm{~min})$ \\
\hline ECOC & $\begin{array}{l}\text { Elemental Carbon/ } \\
\text { Organic Carbon }\end{array}$ & $\begin{array}{l}\text { Semi-continuous, } \\
\text { Sunset Laboratory }\end{array}$ & $\begin{array}{l}\text { Thermal evolution } \\
\text { - optical transmittance } \\
\text { correction } \\
\text { Laser transmittance } \\
\text { (attenuation) } \\
\text { for opt-EC }\end{array}$ & $\begin{array}{l}\text { NIOSH and IMPROVE* } \\
\text { temperature programs }\end{array}$ & $\begin{array}{l}<0.4 \mu \mathrm{g} \mathrm{m}^{-3} \\
\text { (EC, } 40 \text {-min sampling) }\end{array}$ \\
\hline Aethalometer & Aethalometer & AE-21, Magee Scientific & $\begin{array}{l}\text { Transmittance } \\
\text { (attenuation) }\end{array}$ & - & $<0.1 \mu \mathrm{g} \mathrm{m}^{-3}(5 \mathrm{~min})$ \\
\hline
\end{tabular}

forest fire event in Philadelphia when OC was relatively abundant. The tendency that the optical instrument underestimated BC concentrations when OC is relatively abundant contradicts our results. Bae et al. (2007) also showed a similar trend in Gosan, Korea; an Aethalometer gave lower BC values in comparison to the thermal EC measured by a semicontinuous ECOC analyzer, when OC was relatively abundant (their case 2). Although commonly based on an optical method, the property of the Aethalometer might be different from the properties of the MAAP and PSAP. In a comprehensive comparison in Fresno, the United States, Park et al. (2006) showed the ratio of thermal EC (from a Sunset ECOC analyzer) to MAAP_BC was in the range of $0.58-$ 0.73 , consistent with the magnitude relationship in our study. Reisinger et al. (2008) implied that a MAAP instrument overestimated $\mathrm{BC}$ concentrations when the aerosol contained appreciable amounts of brown carbon in winter in Vienna, Austria. This seems consistent with our finding that the MAAP instrument yielded higher values than thermal EC values, especially when an OC fraction that only volatilized at a high temperature was relatively abundant.

\section{Summary}

We conducted optical and thermal observations of BC using four instruments at the top of Mount Tai, Shandong Province, China, in June 2006. The concentrations measured by the instruments were highly correlated and the slopes of the regression lines normally ranged between 1.0 and 1.5 , with an exception of $\sim 2$ for the comparison of MAAP_BC $\left(\mathrm{PM}_{2.5}\right)$ and opt-EC $\left(\mathrm{PM}_{2.5}\right)$. The general agreement enables (1) modelto-observation comparisons of $\mathrm{BC}$ concentrations over this important area to narrow the emission rate, which currently has high uncertainty, (2) accurate analysis of the emission ratio (for example, the $\mathrm{BC} / \mathrm{CO}$ emission ratio), and (3) a more reliable long-term observation using the MAAP instrument at Mount Tai.
In a more detailed analysis, it is inferred that the EC concentrations determined with the IMPROVE* temperature rise program for the ECOC analyzer were higher than those with the NIOSH program by $31 \%$ and showed slightly better agreement with the MAAP_BC values. The MAAP_BC/EC and heated PSAP_BC/EC ratios increased when high OC/EC ratios were reported from the ECOC analyzer. This suggested either that the optical instruments (MAAP and PSAP) overestimated $\mathrm{BC}$ concentrations or that the thermal instrument underestimated EC. Possible explanations for the overestimation of $\mathrm{BC}$ by optical instruments are that the lensing effects influenced the MAAP instrument or that less-volatile OC particles were not removed despite heating of the inlet tube of the PSAP instrument and subsequently increased the absorption by the particles deposited on the filter. The underestimation of EC by the ECOC analyzer would be explained by the possibility that some EC has evolved before the split time between $\mathrm{OC}$ and EC. The fact that the large MAAP_BC/EC ratios are associated with low $\mathrm{NO}_{\mathrm{x}} / \mathrm{NO}_{\mathrm{y}}$ ratios suggests that $\mathrm{BC}$ particles might have been coated by transparent materials after aging and that the optical instruments have overestimated $\mathrm{BC}$ concentrations owing to the lensing effect. In the future, a systematic analysis studying the discrepancy as a function of air mass age should be valuable. Information on size and morphology of BC particles is also necessary because they are known to affect the mass absorption cross section of BC particles in the atmosphere (Bond and Bergstrom, 2006).

\section{Appendix A}

\section{Summary of instruments used in this study}

The acronyms, full names, principles, operation modes, and detection limits of the instruments used in this study are summarized in Table A1. 
Acknowledgements. Professor Yutaka Kondo (University of Tokyo) and Shuichi Hasegawa (National Institute of Environmental Studies) are acknowledged for their valuable comments on the comparisons. Hiroshi Tanimoto (National Institute of Environmental Studies) and Yuesi Wang (Institute of Atmospheric Physics, Chinese Academy of Sciences) are acknowledged for providing data of $\mathrm{NO}_{\mathrm{x}} / \mathrm{NO}_{\mathrm{y}}$ and water soluble chemical species of aerosol particles during the campaign. This work was supported by the Global Environment Research Fund (B-051 and C-081) of the Ministry of the Environment, Ministry of Education, Culture, Sports, Science and Technology (MEXT), Japan.

Edited by: L. Molina

\section{References}

Akimoto, H., Kanaya, Y., and Wang, Z.: The Mt. Tai Experiment: June 2006, Atmos. Chem. Phys. Discuss., in preparation, 2008.

Bae, M.-S., Schauer, J. J., DeMinter, J. T., Turner, J. R., Smith, D., and Cary, R. A.: Validation of a semi-continuous instrument for elemental carbon and organic carbon using a thermal-optical method, Atmos. Environ., 38, 2885-2893, 2004.

Bae, M.-S., Hong, C.-S., Kim, Y. J., Han, J.-S., Moon, K.-J., Kondo, Y., Komazaki, Y., and Miyazaki, Y.: Intercomparison of two different thermal-optical elemental carbons and optical black carbon during ABC-EAREX2005, Atmos. Environ., 41, 2791-2803, 2007.

Bergin, M. H., Cass, G. R., Xu, J., Fang, C., Zeng, L. M., Yu, T., Salmon, L. G., Kiang, C. S., Tang, X. Y., Zhang, Y. H., and Chameides, W. L.: Aerosol radiative, physical, and chemical properties in Beijing during June 1999, J. Geophys. Res., 106(D16), 17969-17980, 2001.

Birch, M. E. and Cary, R. A.: Elemental carbon-based method for monitoring occupational exposures to particulate diesel exhaust, Aerosol Sci. Tech., 25, 221-241, 1996.

Bond, T. C., Anderson, T. L., and Campbell, D.: Calibration and intercomparison of filter-based measurements of visible light absorption by aerosols, Aerosol Sci. Tech., 30, 582-600, 1999.

Bond, T. C., Streets, D. G., Yarber, K. F., Nelson, S. M., Woo, J.H., and Klimont, Z.: A technology-based global inventory of black and organic carbon emissions from combustion, J. Geophys. Res., 109, D14203, doi:10.1029/2003JD003697, 2004.

Bond, T. C. and Bergstrom, R. W.: Light absorption by carbonaceous particles: An investigative review, Aerosol Sci. Tech., 40, 27-67, 2006.

Bond, T. C., Habib, G., and Bergstrom, R. W.: Limitations in the enhancement of visible light absorption due to mixing state, J. Geophys. Res., 111, D20211, doi:10.1029/2006JD007315, 2006.

Cao, J. J., Lee, S. C., Chow, J. C., Watson, J. G., Ho, K. F., Zhang, R. J., Jin, Z. D., Shen, Z. X., Chen, G. C., Kang, Y. M., Zou, S. C., Zhang, L. Z., Qi, S. H., Dai, M. H., Cheng, Y., and Hu, K.: Spatial and seasonal distributions of carbonaceous aerosols over China, J. Geophys. Res., 112, D22S11, doi:10.1029/2006JD008205, 2007.

Carmichael, G. R., Tang, Y., Kurata, G., Uno, I., Streets, D., Woo, J.-H., Huang, H., Yienger, J., Lefer, B., Shetter, R., Blake, D., Atlas, E., Fied, A., Apel, E., Eisele, F., Cantrell, C., Avery, M., Barrick, J., Sachse, G., Brune, W., Sandholm, S., Kondo,
Y., Singh, H., Talbot, R., Bandy, A., Thorton, D., Clarke, A., and Heikes, B.: Regional-scale chemical transport modeling in support of the analysis of observations obtained during the TRACE-P experiment, J. Geophys. Res., 108(D21), 8823, doi:10.1029/2002JD003117, 2003a.

Carmichael, G. R., Tang, Y., Kurata, G., Uno, I., Streets, D. G., Thongboonchoo, N., Woo, J.-H., Guttikunda, S., White, A., Wang, T., Blake, D. R., Atlas, E., Fried, A., Potter, B., Avery, M. A., Sachse, G. W., Sandholm, S. T., Kondo, Y., Talbot, R. W., Bandy, A., Thorton, D., and Clarke, A. D.: Evaluating regional emission estimates using the TRACE-P observations, J. Geophys. Res., 108(D21), 8810, doi:10.1029/2002JD003116, 2003b.

Chow, J. C., Watson, J. G., Crow, D., Lowenthal, D. H., and Merrifield, T.: Comparison of IMPROVE and NIOSH carbon measurements, Aerosol Sci. Tech., 34, 23-34, 2001.

Dan, M., Zhuang, G., Li, X., Tao, H., and Zhuang, Y.: The characteristics of carbonaceous species and their sources in $\mathrm{PM}_{2.5}$ in Beijing, Atmos. Environ., 38, 3443-3452, 2004.

Gao, J., Wang, T., Ding, A., and Liu, C.: Observational study of ozone and carbon monoxide at the summit of mount Tai (1534 ma.s.1.) in central-eastern China, Atmos. Environ., 39, 4779-4791, 2005.

He, K., Yang, F., Ma, Y., Zhang, Q., Yao, X., Chan, C. K., Cadle, S., Chan, T., and Mulawa, P.: The characteristics of $\mathrm{PM}_{2.5}$ in Beijing, China, Atmos. Environ., 35, 4959-4970, 2001.

Hitzenberger, R., Petzold, A., Bauer, H., Ctyroky, P., Pouresmaeil, P., Laskus, L., and Puxbaum, H.: Intercomparison of thermal and optical measurement methods for elemental carbon and black carbon at an urban location, Environ. Sci. Technol., 40, 63776383, 2006.

IPCC: Climate Change 2007 - The Physical Science Basis, Contribution of Working Group I to the Fourth Assessment Report of the Intergovernmental Panel on Climate Change, edited by: Solomon, S., Qin, D., Manning, M., Chen, Z., Marquis, M., Averyt, K. B., Tignor, M., and Miller, H. L., Cambridge University Press, Cambridge, United Kingdom and New York, NY, USA, 2007.

Jeong, C.-H., Hopke, P. K., Kim, E., and Lee, D.-W.: The comparison between thermal-optical transmittance elemental carbon and Aethalometer black carbon measured at multiple monitoring sites, Atmos. Environ., 38, 5193-5204, 2004.

Kanaya, Y., Pochanart, P., Liu, Y., Tanimoto, H., Kato, S., Suthawaree, J., Inomata, S., Taketani, F., Okuzawa, K., Kawamura, K., Akimoto, H., and Wang, Z.: Rates and regimes of photochemical ozone production over Central East China in June 2006: A box model analysis using comprehensive measurements of ozone precursors, Atmos. Chem. Phys. Discuss., in preparation, 2008.

Kleinman, L. I., Daum, P. H., Lee, Y.-N., Senum, G. I., Springston, S. R., Wang, J., Berkowitz, C., Hubbe, J., Zaveri, R. A., Brechtel, F. J., Jayne, J., Onasch, T. B., and Worsnop, D.: Aircraft observations of aerosol composition and ageing in New England and Mid-Atlantic States during the summer 2002 New England Air Quality Study field campaign, J. Geophys. Res., 112, D09310, doi:10.1029/2006JD007786, 2007.

Kondo, Y., Komazaki, Y., Miyazaki, Y., Moteki, N., Takegawa, N., Kodama, D., Deguchi, S., Nogami, M., Fukuda, M., Miyakawa, T., Morino, Y., Koike, M., Sakurai, H., and Ehara, K.: Temporal variations of elemental carbon in Tokyo, J. Geophys. Res., 111, D12205, doi:10.1029/2005JD006257, 2006. 
Li, C., Marufu, L. T., Dickerson, R. R., Li, Z., Wen, T., Wang, Y., Wang, P., Chen, H., and Stehr, J. W.: In situ measurements of trace gases and aerosol optical properties at a rural site in northern China during East Asian Study of Tropospheric Aerosols: An International Regional Experiment 2005, J. Geophys. Res., 112, D22S04, doi:10.1029/2006JD007592, 2007.

Li, J., Wang, Z., Akimoto, H., Yamaji, K., Takigawa, M., Pochanart, P., Liu, Y., Tanimoto, H., and Kanaya, Y.: Near-ground ozone source attributions and outflow in central eastern China during MTX2006, Atmos. Chem. Phys., 8, 7335-7351, 2008, http://www.atmos-chem-phys.net/8/7335/2008/.

Moteki, N., Kondo, Y., Miyazaki, Y., Takegawa, N., Komazaki, Y., Kurata, G., Shirai, T., Blake, D. R., Miyakawa, T., and Koike, M.: Evolution of mixing state of black carbon particles: Aircraft measurements over the western Pacific in March 2004, Geophys. Res. Lett., 34, L11803, doi:10.1029/2006GL028943, 2007.

Park, K., Chow, J. C., Watson, J. G., Trimble, D. L., Doraiswamy, P., Arnott, W. P., Stroud, K. R., Bowers, K., Bode, R., Petzold, A., and Hansen, A. D. A.: Comparison of continuous and filterbased carbon measurements at the Fresno supersite, J. Air Waste Manage. Assoc., 56, 474-491, 2006.

Petzold, A. and Schönlinner, M.: Multi-angle absorption photometry - a new method for the measurement of aerosol light absorption and atmospheric black carbon, J. Aerosol Sci., 35, 421-441, 2004.

Petzold, A., Schloesser, H., Sheridan, P. J., Arnott, W. P., Ogren, J. A., and Virkkula, A.: Evaluation of multiangle absorption photometry for measuring aerosol light absorption, Aerosol Sci. Tech., 39, 40-51, 2005.

Reisinger, P., Wonaschütz, A., Hitzenberger, R., Petzold, A., Bauer, H., Jankowski, N., Puxbaum, H., Chi, X., and Maenhaut, W.: Intercomparison of measurement techniques for black or elemental carbon under urban background conditions in wintertime: Influence of biomass combustion, Environ. Sci. Technol., 42, 884$889,2008$.

Shiraiwa, M., Kondo, Y., Moteki, N., Takegawa, N., Miyazaki, Y., and Blake, D. R.: Evolution of mixing state of black carbon in polluted air from Tokyo, Geophys. Res. Lett., 34, L16803, doi:10.1029/2007GL029819, 2007.

Slowik, J. G., Cross, E. S., Han, J.-H., Davidovits, P., Onasch, T. B., Jayne, J. T., Williams, L. R., Canagaratna, M. R., Worsnop, D. R., Chakrabarty, R. K., Moosmüller, H., Arnott, W. P., Schwarz, J. P., Gao, R.-S., Fahey, D. W., Kok, G. L., and Petzold, A.: An Inter-comparison of instruments measuring black carbon content of soot particles, Aerosol Sci. Tech., 41, 295-314, 2007.

Streets, D. G., Bond, T. C., Carmichael, G. R., Fernandes, S. D., Fu, Q., He, D., Klimont, Z., Nelson, S. M., Tsai, N. Y., Wang, M. Q., Woo, J.-H., and Yarber, K. F.: An inventory of gaseous and primary aerosol emissions in Asia in the year 2000, J. Geophys. Res., 108(D21), 8809, doi:10.1029/2002JD003093, 2003.
Uno, I., Carmichael, G. R., Streets, D., Satake, S., Takemura, T., Woo, J.-H., Uematsu, M., and Ohta, S.: Analysis of surface black carbon distributions during ACE-Asia using a regional-scale aerosol model, J. Geophys. Res., 108(D23), 8636, doi:10.1029/2002JD003252, 2003.

Wang, T., Wong, C. H., Cheung, T. F., Blake, D. R., Arimoto, R., Baumann, K., Tang, J., Ding, G. A., Yu, X. M., Li, Y. S., Streets, D. G., and Simpson, I. J.: Relationships of trace gases and aerosols and the emission characteristics at Lin'an, a rural site in eastern China, during spring 2001, J. Geophys. Res., 109, D19S05, doi:10.1029/2003JD004119, 2004.

Woo, J.-H., Streets, D. G., Carmichael, G. R., Tang, Y., Yoo, B., Lee, W.-C., Thongboonchoo, N., Pinnock, S., Kurata, G., Uno, I., Fu, Q., Vay, S., Sachse, G. W., Blake, D. R., Fried, A., and Thornton, D. C.: Contribution of biomass and biofuel emissions to trace gas distributions in Asia during the TRACE-P experiment, J. Geophys. Res., 108(D21), 8812, doi:10.1029/2002JD003200, 2003.

Xu, J., Bergin, M. H., Yu, X., Liu, G., Zhao, J., Carrico, C. M., and Baumann, K.: Measurement of aerosol chemical, physical and radiative properties in the Yangtze delta region of China, Atmos. Environ., 36, 161-173, 2002.

Yamaji, K., Takigawa, M., Li, J., Kanaya, Y., Pochanart, P., Liu, Y., Komazaki, Y., Ohara, T., Uno, T., Wang, Z., and Akimoto, H.: Evaluating impact of field burning of crop residue on air pollutions for the Mount Tai Experiment 2006 using regional model, Atmos. Chem. Phys. Discuss., in preparation, 2008.

Yan, P., Tang, J., Huang, J., Mao, J. T., Zhou, X.J., Liu, Q., Wang, Z. F., and Zhou, H. G.: The measurement of aerosol optical properties at a rural site in Northern China, Atmos. Chem. Phys., 8, 2229-2242, 2008, http://www.atmos-chem-phys.net/8/2229/2008/.

Yang, F., He, K., Ye, B., Chen, X., Cha, L., Cadle, S. H., Chan, T., and Mulawa, P. A.: One-year record of organic and elemental carbon in fine particles in downtown Beijing and Shanghai, Atmos. Chem. Phys., 5, 1449-1457, 2005, http://www.atmos-chem-phys.net/5/1449/2005/.

Yang, H., Yu, J. Z., Ho, S. S. H., Xu, J., Wu, W.-S., Wan, C. H., Wang, X., Wang, X., and Wang, L.: The chemical composition of inorganic and carbonaceous materials in $\mathrm{PM}_{2.5}$ in Nanjing, China, Atmos. Environ., 39, 3735-3749, 2005.

Ye, B., Ji, X., Yang, H., Yao, X., Chan, C. K., Cadlec, S. H., Chan, T., and Mulawa, P. A.: Concentration and chemical composition of $\mathrm{PM}_{2.5}$ in Shanghai for a 1-year period, Atmos. Environ., 37, 499-510, 2003. 